\title{
O Conselho Nacional de Justiça: o Fórum da Saúde e o excesso de judicialização
}

The National Council of Justice: the Health Forum and the excessive judicialization

El Consejo Nacional de Justicia: el Foro de la salud y la excesiva judicialización

\section{Edith Maria Barbosa Ramos ${ }^{1}$ Isadora Moraes Diniz² Amanda Silva Madureira ${ }^{3}$}

Resumo: O Conselho Nacional de Justiça pretende ocupar o papel de protagonista do necessário debate que precisa ser travado em torno da judicialização da saúde. Para tanto, desde 2010, vem conduzindo uma política pública judiciária para o aprimoramento da prestação jurisdicional nas demandas de saúde através da criação do Fórum do Judiciário para a Saúde, desta feita, tem-se como objetivo principal do artigo avaliar a eficácia dessa política judiciária conduzida pelo CNJ no campo da judicialização da saúde.

Palavras-chave: Sistema de Justiça, Direito à Saúde, Judicialização

Abstract: The National Council of Justice (CNJ) intends to take up the role of protagonist of the necessary debate that needs to be developed around the judicialization of health. To this end, since 2010, it has been conducting a judicial public policy for the improvement of judicial services in healthcare demands by creating the Judicial Forum for Healthcare; therefore, the main purpose of the article to evaluate the effectiveness of this judicial policy conducted by the $\mathrm{CNJ}$ in the field of judicialization of healthcare.

Keywords: Justice System, Right to Healthcare, Judicialization.

Resumen: El Consejo Nacional de Justicia (CNJ) tiene la intención de ser el principal protagonista del debate necesario alrededor de la judicialización de la salud. Para eso, desde 2010, ha conduzido la realización de una política pública judicial para mejorar los servicios judiciales en demandas de salud por la creación del Foro Judicial para la Salud. Este articulo tiene el propósito principal evaluar la eficacia de la política judicial realizada por el CNJ en el campo de la judicialización de la salud.

Palabras-Ilave: Sistema de Justicia, Derecho a la salud, judicialización

\footnotetext{
1 Doutora em Políticas Públicas pela Universidade Federal do Maranhão. Mestre em Direito pela Universidade Federal de Minas Gerais. Graduada em Direito pela Universidade Federal do Maranhão. Professora do Departamento de Direito e do Mestrado em Direito e Instituições do Sistema de Justiça da Universidade Federal do Maranhão. Coordenadora do Núcleo de Estudos em Direito Sanitário (NEDISA) da UFMA. Professora e Pesquisadora da Universidade do CEUMA. Professora do IMEC. Professora da FACAM. Membro Convidado da Rede Ibero-Americana de Direito Sanitário. E-mail: edithramosadv@yahoo.com.br

${ }^{2}$ Mestre em Direito e Instituições do Sistema de Justiça pela Universidade Federal do Maranhão. Professora do Instituto Maranhense de Ensino e Cultura. Membro do Núcleo de Estudos em Direito Sanitário da Universidade Federal do Maranhão. Assessora do Tribunal de Justiça do Estado do Maranhão.

3 Doutoranda em Políticas Públicas (UFMA). Mestre em Direito pela Universidade Federal de Santa Catarina (UFSC). Graduada em Direito pela Universidade Federal do Maranhão. Professora da Universidade CEUMA. Pesquisadora do Núcleo de Estudos em Direito Sanitário.
} 


\section{Introdução}

A Constituição Federal brasileira de 1988 foi a primeira a tratar a saúde como direito, reconhecendo, em seus artigos 6ำ e 196, o caráter de direito fundamental, que, para a sua concretização, exige a assunção de deveres pelo Estado (1).

Em um contexto em que a efetividade dos direitos à saúde é condicionada à reserva das capacidades financeiras do Estado (2), somando-se a isso o alto grau de abstração e complexidade para a efetivação deste direito, tem se disseminando um fenômeno que ficou conhecido como 'judicialização' da saúde (3), que significa a transferência das decisões sobre políticas públicas em saúde para o Poder Judiciário.

Dessa forma, a falta, a incompletude ou a má gestão governamental das políticas públicas (4) na área desencadeiam alta demanda do Poder Judiciário, transformando-o no último, às vezes no único, recurso para a garantia da saúde (5), da vida e da dignidade da pessoa humana. Nesse cenário, as instituições do sistema de justiça, especialmente o Poder Judiciário, assumiram papel fundamental na efetivação do direito à saúde.

Todavia, o que se observa é que os juristas enfrentam dificuldade em traçar os limites de garantia. Assim, casuísmos e sentimentalismo se tornaram cada vez mais frequentes, predominando a compreensão de que o direito à saúde possui somente uma dimensão subjetiva, não podendo ser denegado de forma alguma, posicionamento que dificulta a necessária diferenciação entre demandas originadas de uma real omissão do Poder Público na concretização do direito à saúde e aquelas que pleiteiam um benefício que não passa de um mero interesse individual (1).

A inexistência de parâmetros institucionais para a aferição dos limites e possibilidades do direito à saúde propicia a existência de sentenças judiciais extremamente díspares, uma vez que os juízes, não raro, por desconhecerem as questões técnicas e científicas imbricadas nas demandas de saúde, prolatam sentenças que não compreendem a real dimensão da garantia, deixando-se levar pelo forte apelo emocional dos casos que apreciam e desconsiderando as opções feitas pelos Poderes Executivo e Legislativo, e também pela sociedade, as quais também são escolhas legítimas (6).

Dessa forma, faz-se necessária a criação de critérios mais claros, que permitam ao Poder Judiciário agir de modo equilibrado, de um lado em relação ao cumprimento de sua missão constitucional de proteção dos direitos fundamentais e, de outro, enquanto Instituição atenta às limitações econômicas do Estado e à separação harmônica dos poderes (7). 
O Conselho Nacional de Justiça pretende ocupar o papel de ator principal do necessário debate que precisa ser travado em torno do tema (8). Para tanto, desde 2010, conduz uma política pública judiciária para o aprimoramento da prestação jurisdicional nas demandas de saúde através da criação do Fórum do Judiciário para a Saúde. Nesse sentido, o objetivo geral da pesquisa é avaliar a eficácia da política judiciária conduzida pelo CNJ no campo da 'judicialização' da saúde, notadamente, a funcionalidade do Comitê Executivo Nacional.

Dessa feita, foram objetivos específicos do presente trabalho: analisar a atuação do CNJ, por meio do Fórum Nacional de Saúde, como órgão protagonista no processo de redução da judicialização da saúde e garantia da eficácia desse importante direito social.

\section{Método}

A pesquisa partiu da premissa de que as contradições são inerentes aos processos sociais, contradições que, no contraponto da tese e antítese, acabam por propiciar o desenvolvimento dos próprios fenômenos, que, por sua vez, somente podem ser apreendidos a partir da observação direta da realidade, desenvolvida a partir da interlocução com os personagens envolvidos na pesquisa (9).

Para a apropriação do conteúdo da política pública judiciária desenvolvida pelo CNJ na seara da 'judicialização' da saúde, foram adotados os seguintes procedimentos metodológicos: levantamento bibliográfico e documental, coleta de dados através de entrevistas semiestruturadas e aplicação de questionários aos responsáveis pelo Fórum Nacional de Saúde.

Os dados coletados pela pesquisa empírica realizada foram analisados a fim de possibilitar a verificação da eficácia (10) dos instrumentos estabelecidos pelo CNJ para o aprimoramento da prestação jurisdicional nas demandas de saúde, além de seus limites e possibilidades. O Comitê Executivo Nacional tem por função o exercício, em nível nacional, da coordenação do Fórum da Saúde e a execução de ações consideradas relevantes para a melhoria da prestação jurisdicional nas demandas de saúde.

O Comitê Executivo Nacional está sob a direção da Conselheira do CNJ Deborah Ciocci, sendo composto ainda por juízes, servidores do Poder Judiciário especialistas em direito sanitário, além de representantes do Ministério da Saúde, da Agência Nacional de 
Saúde Suplementar, da Agência Nacional de Vigilância Sanitária, do Conselho Nacional de Secretários de Saúde e do Conselho Nacional de Secretarias Municipais de Saúde.

Realizou-se entrevista com a Conselheira do CNJ, em Brasília/DF, a fim de verificar como ocorre a condução nacional dos trabalhos do Fórum da Saúde e averiguar a eficácia dos atos normativos do Conselho.

O roteiro da entrevista semiestruturada compôs-se de dez perguntas. Apenas duas delas foram respondidas pela Conselheira, as demais foram respondidas por um assessor seu. As perguntas realizadas diretamente à Coordenadora do Comitê Executivo Nacional foram as seguintes:

1. Qual é a percepção de Vossa Excelência sobre a judicialização da saúde e o Fórum Nacional do Judiciário para a saúde?

2. O Fórum foi criado há quase cinco anos durante a presidência do Min. Gilmar Mendes, cujo mandato frente ao STF e CNJ se destacou pela defesa aos direitos e garantias fundamentais. Passados 5 anos da sua criação, Vossa Excelência avalia que as ações do Fórum ainda estão entre as prioridades do CNJ?

As perguntas dirigidas à Assessoria foram:

1. Qual a periodicidade das reuniões do Fórum?

2. Existe uma agenda de tarefas a ser cumprida em 2015 ?

3. Como o Fórum realiza o monitoramento das ações judiciais que envolvem prestações de assistência à saúde?

4. Além da quantificação do número de ações, O Fórum já realizou algum estudo sobre a judicializaçao da saúde?

5. Como é a infraestrutura e recursos humanos disponíveis para o Fórum?

6. Há um espaço de funcionamento próprio e servidores exclusivamente designados para a realização dos estudos sobre a judicializacao?

7. Quais medidas concretas e normativas voltadas à otimização das rotinas processuais e prevenção de conflitos judiciais em saúde adotadas pelo Fórum que Vossa Excelência destacaria?

8. Há um acompanhamento periódico das medidas recomendadas pelo CNJ que já foram adotadas pelos Tribunais brasileiros? 


\section{Resultados}

Em suas respostas, a Conselheira destacou que entende o Fórum da Saúde como 'um trabalho multidisciplinar que contribui para a desjudicialização, que é a nova meta institucional do CNJ', expressa na Portaria nํ. 16/2015. Segundo ela, as ações do Fórum ainda estão entre as prioridades do Conselho Nacional de Justiça, tanto é que a referida portaria "prevê como uma das metas do órgão a garantia dos direitos fundamentais, chamando a sociedade para participar [desse processo]".

Sobre o primeiro questionamento o assessor informou que as reuniões acontecem, geralmente, uma vez por mês, mas que, em determinadas circunstâncias, há reuniões extraordinárias para a apreciação de questões específicas. Ele disse, ainda, que o Fórum "é um ambiente permanente de debate, de discussões virtuais".

Com relação à primeira parte do segundo questionamento, o assessor disse que

Com base na Resolução no 107, o Conselheiro Milton Nobre [primeiro coordenador do Fórum] pediu que fosse criado um sistema de acompanhamento - o Sistema da Resolução 107, que armazena os dados enviados pelos Tribunais sobre as ações de saúde, a partir dos quais são retirados relatórios.

Esses relatórios permitem o monitoramento das ações judiciais envolvendo prestações de assistência à saúde.

O entrevistado reconheceu, todavia, que o monitoramento realizado pelo $\mathrm{CNJ}$ apresenta muitas falhas, pois verificaram que o quantitativo de demandas de saúde divulgado no site do Conselho não coincide com os números enviados por algumas Secretarias de Saúde, sendo os últimos sempre maiores. Ele explicou que é dos Tribunais brasileiros a responsabilidade de alimentar o Sistema da Resolução no 107 e que o número aquém do quantitativo de ações de saúde realmente em tramitação pode ser atribuído ao fato de que os Tribunais não sabem quais dados cadastrar no Sistema, já que cada Tribunal tem um modo próprio de classificar as ações envolvendo prestação de saúde, embora exista um padrão sugerido pelo CNJ (Sistema de Gestão de Tabelas Processuais Unificadas), que, por não ser uma obrigação legal, acaba inobservado pelos Tribunais.

O assessor realçou, ainda, que é necessário a criação de um padrão melhor para o levantamento dos dados, talvez sendo o caso de se realizar oficinas nos Tribunais brasileiros de modo a possibilitar-lhes o melhor manuseio do Sistema da Resolução no 107. Além disso, frisou que "apesar de haver uma Resolução do CNJ, os Tribunais acabam não mandando 
os dados, porque é uma ação permanente que acaba se perdendo pela mudança de gestão".

O entrevistado disse, sobre o quinto questionamento, que a infraestrutura utilizada pelo Fórum é a estrutura de gabinete do coordenador do Fórum, citando que ele, por exemplo, é a um só tempo assessor de processos da Conselheira Deborah Ciocci e do Fórum da Saúde por ela coordenado. Pontuou, ainda, que "recentemente (há um mês) foi criado no CNJ um Núcleo de Apoio às Comissões, mas que tem apenas três servidores que ainda estão em fase de levantamento de quais comissões e projetos existem. A ideia é que possam auxiliar todos os projetos e comissões".

Para o sexto questionamento, o assessor afirmou que as principais medidas para a otimização das rotinas processuais e prevenção de conflitos judiciais em saúde tomadas pelo CNJ foi a edição dos seguintes atos normativos: Resolução no 107/2010, Recomendação n 31/2010, Recomendação nํ 36/2011 e Recomendação no 43/2013.

A Resolução no 107/2010 instituiu o Fórum do Judiciário para a Saúde; a Recomendação no 31/2010 prevê uma série de orientações aos Tribunais, magistrados e escolas de formação de juízes; a Recomendação nำ 36/2011 estabelece orientações destinadas a assegurar maior eficiência na solução das demandas judiciais; e a Recomendação n 43/2013 que recomenda a especialização das varas para processa e julgar ações envolvendo o direito à saúde.

A Resolução nº 107/2010 atribuiu ao Fórum a tarefa de proposição, além de medidas normativas, de medidas concretas voltadas à otimização de rotinas processuais, à organização de rotinas processuais, à organização e estruturação de unidades judiciárias especializada, à prevenção de conflitos judiciais e à definição de estratégias nas questões de direito à saúde. No entanto, após quase cinco anos de existência do Fórum da Saúde ainda não há nenhum grande projeto objetivando o alcance de tais fins. Verificou-se que, em verdade, o Fórum atribuiu a responsabilidade da criação dessas medidas concretas para os Tribunais e a efetiva criação delas dependerá do grau de comprometimento destes órgãos com a questão da judicialização da saúde.

Em relação ao oitavo questionamento o assessor informou que

foi criado pelo CNJ um processo eletrônico de acompanhamento de cumprimento de decisões, de consulta pública (Processo 0003398/62.2012.2.0000). Nesse processo, há o acompanhamento da Recomendação oㅜ 31. Sempre pedem informações, de 6 em 6 meses, sobre a estrutura que o Tribunal está disponibilizando ao Comitê Executivo Estadual. 


\section{Considerações Finais}

A falta de conhecimento da situação dos Estados, por parte do Fórum Nacional de Saúde, prejudica a própria gestão da política, uma vez que sem um diagnóstico das deficiências dos entes não há como se pensar em soluções para os problemas gerados pela judicialização da saúde.

Conforme se observa, o Conselho Nacional de Justiça, por depender dos Tribunais (que muitas vezes não estão envolvidos na política judiciária), tem tido dificuldades para quantificar as ações de saúde, o que é preocupante porque sem um cenário fidedigno do número e do tipo de ações é muito difícil oferecer soluções para os problemas gerados pela judicialização da saúde.

O Fórum não vem cumprindo de modo efetivo o que a Resolução nำ 107/2010 (digase, de caráter vinculante ${ }^{4}$ ) determina que ele faça: "o monitoramento das ações judiciais que envolvam prestações de assistência à saúde, como o fornecimento de medicamentos, produtos ou insumos em geral e disponibilização de leitos hospitalares". Essa inefetividade foi constatada por duas razões: i) porque a quantidade de demandas envolvendo o direito à saúde constante no site do Conselho não condiz com a realidade e ii) o quadro não permite verificar os diversos assuntos sobre os quais as demandas versam ${ }^{5}$.

Ressalte-se que até o momento o CNJ ainda não realizou qualquer estudo sobre a judicialização da saúde e, a partir dos apanhados analisados, essa não é a prioridade do órgão, 'a prioridade é encontrar mecanismos para diminuir as ações'. Percebeu-se claramente que a política para o aprimoramento da prestação jurisdicional em saúde é conduzida sem estar embasada em estudos sobre o panorama da judicialização no Brasil, o que causa perplexidade porque é muito difícil oferecer soluções efetivas se não se conhece o perfil e a quantidade dessas ações, as dificuldades específicas de cada Estado brasileiro no enfrentamento do tema, dentre outros fatores.

O CNJ, ao longo de sua existência, vem lançando uma série de projetos não só na área de gestão administrativa do Judiciário, mas também de garantia aos direitos humanos fundamentais ${ }^{6}$, sem, todavia, contar com a infraestrutura adequada para a execução e

\footnotetext{
4 Por força do art. 102 \$5 do Regimento Interno do CNJ, as resoluções do órgão têm força vinculante após a publicação no Diário da Justiça eletrônico e no sítio eletrônico da instituição.

5 CONSELHO NACIONAL DE JUSTIÇA. 2010. Quantidade de demandas de saúde nos Tribunais

6 Projetos que pretendem trabalhar uma infinidade de questões: conflitos de terras e trabalho escravo, assuntos fundiários, trabalho escravo, adoção de crianças e adolescentes, reconhecimento de paternidade,
} 
acompanhamento desses projetos. No caso do Fórum da Saúde, isso resulta na pouca eficácia que tem ao longo dos anos, pois, apesar de promover anualmente encontros, as suas recomendações e enunciados têm pouca penetração na jurisprudência brasileira e ainda não se conseguiu lançar em nível nacional qualquer medida concreta para 0 aprimoramento da prestação jurisdicional nas demandas de saúde ou para a prevenção de novos conflitos.

Nesse contexto, observa-se que a atuação do Fórum da Saúde até o momento não ultrapassou o plano normativo, o que se considera insuficiente, na medida em que o plano dos fatos não se modifica apenas a partir de normas, sobretudo, quando editadas sem força vinculante (as recomendações têm apenas caráter de orientações dirigidas aos Tribunais e magistrados).

Em consulta ao processo eletrônico referido, verificou-se que o CNJ através dele divulga os eventos promovidos pelo Fórum, bem como solicita informações dos Tribunais sobre as providências já adotadas para o cumprimento da Recomendação, todavia, não foi possível observar as informações repassadas pelos Tribunais.

Entende-se que esse acompanhamento por meio do processo eletrônico, que não é atualizado desde $29 / 3 / 2014^{7}$, é insuficiente, fazendo-se necessário um contato mais direto do CNJ com os Tribunais a fim de se certificar sobre a realidade das informações repassadas para e das dificuldades enfrentadas no cumprimento dos atos normativos do órgão. Conforme se observa, o próprio Conselho reconhece que as estratégias de divulgação das ações do Fórum são insuficientes, não conseguindo atingir os magistrados. Nesse contexto, tem-se que é preciso investir mais na divulgação das ações do Fórum da Saúde, até como forma de ampliar os participantes nos debates que acontecem nos encontros que vem sendo promovidos pelo CNJ para a discussão de temas relacionados à judicialização da saúde.

ressocialização dos presos e egressos do sistema carcerário, métodos consensuais de resolução de conflitos, doação de órgãos, células e tecidos, judicialização da saúde, exploração sexual, trabalhos forçados e retirada de órgãos e violência doméstica contra a mulher.

7 Brasil. Conselho Nacional de Justiça. Sistema de processo eletrônico. 2015. Disponível em:<https://www.cnj.jus.br/ecnj/index.php>. Acesso em: 20 mar. 2015 (11). 


\section{Referências}

1 - Ramos, EMB. Universalidade do direito à saúde. São Luís: EDUFMA; 2014.

2 - Amaral G. Direito, escassez e escolha: em busca de critérios jurídicos para lidar com a escassez de recursos e as decisões trágicas. Rio de Janeiro: Renovar; 2001.

3 - Delduque MC, Marques SB, Ciarlini A. Judicialização das políticas de saúde no Brasil. In: Alves, SMC, Delduque MC, Dino Neto Nicolao, organizadores. Direito sanitário em perspectiva. Brasília: ESMPU: FIOCRUZ; 2013.

4 - Tate CN, Vallinder T. The global expansion of judicial power. New York: New York University; 1995.

5 - Souza JM. Diálogo institucional e direito à saúde. Salvador: JusPODIVM; 2013.

6 - Werner PUP. O Direito Social e o Direito Público Subjetivo à Saúde: o desafio de compreender um Direito com duas faces, Revista de Direito Sanitário, 2008, 9 (2): 92-131.

7 - Barroso LR. Judicialização, ativismo judicial e legitimidade democrática. Thesis . 2012 [Acesso em 16 abr. 2015]. 5(1): 23-32. Disponível em http://www.epublicacoes.ueri.br/index.php/synthesis/article/view/7433/5388

8 - Sampaio JAL. O Conselho Nacional de Justiça e a Independência do Judiciário. Belo Horizonte: Del Rey; 2007.

9 - Marx K. Contribuição à crítica da economia política. Tradução Florestan Fernandes. São Paulo: Expressão Popular; 2008.

10 - Silva MOS Avaliação de políticas e programas sociais: aspectos conceituais e metodológicos. In: Silva MOS. Avaliação de políticas públicas: teoria e prática. São Paulo: Veras; 2001.

11 - Brasil. Conselho Nacional de Justiça. Regimento Interno do CNJ. [Acesso em 19 mai 2015]. Disponível em:

http://www.cnj.jus.br/files/conteudo/arquivo/2015/10/b8953e0554207c0f4fb95a29e9326532. pdf. 